\title{
Transmissão de Conhecimentos Religiosos NA Sociedade da InFormaÇão e Sua Tutela JuRÍdica em Face do Direito Ambiental Constitucional
}

\author{
Celso Antonio Pacheco Fiorillo* \\ Renata Marques Ferreira* *
}

\begin{abstract}
1 Introdução. 2 Liberdade de crença e a tutela jurídica das religiões em face do meio ambiente cultural: as religiões associadas às questões existenciais surgidas em diferentes culturas e, em nosso país, vinculadas ao modo de viver dos diferentes grupos formadores da sociedade brasileira (Arts. 215 e 216 da CF). 3 Tutela jurídica da religião em face das culturas indígenas. 4 Tutela jurídica da religião em face das culturas afro-brasileiras. 5 Tutela jurídica da religião em face das culturas de outros grupos participantes do processo civilizatório nacional: as igrejas cristãs. 5.1 Tutela jurídica do catolicismo. 5.2 Tutela do protestantismo (evangélicos). 6 Transmissão de conhecimentos religiosos na sociedade da informação. 6.1 A transmissão de conhecimentos religiosos na sociedade da informação como manifestação cultural dos grupos participantes do processo civilizatório nacional em face da tutela jurídica do meio ambiente digital. 7 Conclusão. Referências.
\end{abstract}

\section{RESUMO}

A transmissão de conhecimentos religiosos, associada às questões existenciais surgidas em diferentes culturas e, em nosso país, vinculada aos modos de viver dos diferentes grupos formadores da sociedade brasileira, tem seu balizamento definido em nosso Estado Democrático de Direito delimitada de forma abrangente a partir do conceito jurídico de religião como um

* Advogado. Militante há mais de 30 anos e atual Presidente da Comissão Permanente do Meio Ambiente da OAB/SP, é o primeiro professor livre-docente em Direito Ambiental do Brasil, sendo também Doutor e Mestre em Direito das Relações Sociais. Director Académico do Congresso de Derecho Ambiental Contemporáneo España/Brasil-Universidade de Salamanca(ESPANHA) e Miembro colaborador del Grupo de Investigación Reconocido IUDICIUM: Grupo de Estudios Procesales de la Universidad de Salamanca (ESPANHA). É, também, Professor convidado visitante da Escola Superior de Tecnologia do Instituto Politécnico de Tomar (PORTUGAL). Professor Visitante/Pesquisador da Facoltà di Giurisprudenza della Seconda Università Degli Studi di Napoli (ITALIA) e Professor Permanente do Programa de Mestrado em Direito da UNINOVE-SP. E-mail: <capfiorillo@terra.com.br>.

** Pós-Doutora em Engenharia Ambiental e Hidráulica (Contaminação e remediação de solos) - Escola Politécnica - POLI/USP. Doutora em Direito das Relações Sociais (sub área de Direitos Difusos e Coletivos-Direito Ambiental) pela Pontifícia Universidade Católica de São Paulo . Mestre em Direito das Relações Sociais (sub área de Direitos Difusos e Coletivos-Direito Ambiental Tributário) pela Pontifícia Universidade Católica de São Paulo. Professora, Orientadora e Pesquisadora do Programa de Mestrado em Saúde Ambiental da FMU - Tutela Jurídica do Meio Ambiente. Professora convidada da Escola Superior de Advocacia da Ordem dos Advogados do Brasil - Seção de São Paulo (ESA-OAB/SP). Coordenadora do Grupo de Trabalho de Tutela Jurídica da Saúde Ambiental bem como de Tutela Jurídica da Governança Corporativa Sustentável da Comissão do Meio Ambiente da Ordem dos Advogados do Brasil-Seção de São Paulo (OAB/ SP). E-mail: <renferreira@uol.com.br>. 
bem cultural estruturado em face da tutela jurídica constitucional do meio ambiente cultural (arts. 215/216 da Carta Magna). Destarte pode ser validamente desenvolvida e propalada por diferentes formas, processos ou veículos existentes no âmbito da comunicação social (Art.220 e segs da CF) e tutelada juridicamente no plano do meio ambiente digital como efetiva e eficiente forma de transmitir seus valores na sociedade da informação em que vivemos. O tema não se esgota, pois tão somente na "convergência de três normas constitucionais: a que prevê o ensino religioso (artigo 210, parágrafo $1^{\circ}$ ), a que assegura a liberdade religiosa (artigo $5^{\circ}$, inciso VI) e a que consagra o princípio da laicidade do Estado (artigo 19, inciso I)", porém necessariamente a partir de interpretação constitucional sistemática mais ampla (direito ambiental constitucional) com a necessária aplicação do regramento jurídico destinado a tutelar o uso dos espaços difusos destinados não só à transmissão de conhecimentos religiosos na sociedade em que vivemos, mas à disseminação de toda e qualquer manifestação do pensamento, à criação e expressão da pessoa humana visando a assegurar sua dignidade (art.1 ${ }^{\circ}$, III).

Palavras-chave: Religião. Bem cultural. Meio Ambiente Cultural. Meio Ambiente Digital. Direito ambiental constitucional.

\section{INTRODUÇÃO}

Ao dar início, em 30 de agosto de 2017, ao julgamento da Ação Direta de Inconstitucionalidade (ADI) 4439, ${ }^{1}$ visando a interpretar à luz da Carta Magna em vigor a adequação do ensino religioso em escolas da rede oficial de ensino do país, o Plenário do Supremo Tribunal Federal (STF) entendeu por bem não só apreciar o tema do referido ensino religioso nas escolas públicas de Ensino Fundamental brasileiras em face de nossa Constituição Federal (se deve ter natureza não confessional, isto é, desvinculado de religiões específicas) como evidentemente estabelecer em que medida o ensino vinculado à religião, como forma organizada e sistemática de transmissão de conhecimentos utilizada pelos humanos para instruir e educar seus semelhantes, pode ser validamente propalado em escolas da rede oficial de Ensino Fundamental do País (o Ensino Fundamental é o nome dado a uma das etapas da educação básica no Brasil com duração de nove anos, sendo a matrícula obrigatória para todas as pessoas com idade entre 6 e 14 anos).

Assim, o Supremo Tribunal Federal, preocupado em salientar que o ensino religioso em escolas públicas de Ensino Fundamental violaria a laicidade porque identifica Estado e Igreja (o que é vedado pela Constituição Federal), atento ao que seria um indevido uso dos espaços públicos em proveito de uma determinada religião e entendendo que a solução para a discussão adequada da lide se encontrava na "convergência de três normas constitucionais: a que prevê o ensino religioso (artigo 210, parágrafo $1^{\circ}$ ), a que assegura a liberdade religiosa (artigo $5^{\circ}$, inciso VI) e a que consagra o princípio da laicidade do Estado (artigo 19, inciso I)" (BRASIL, 2017, online), propiciou a oportunidade de se analisar em face de interpretação sistemática de nossa Carta Magna, em que medida a transmissão de conhecimentos religiosos destinada 
não só aos estudantes de escolas públicas de Ensino Fundamental em nosso País, mas em face de todos os brasileiros e estrangeiros residentes no Brasil (Art.5, caput da CF), tem seu balizamento definido em nosso Estado Democrático de Direito de forma bem mais complexa e ampla tendo em vista o conceito jurídico de religião como um bem cultural estruturado em face do Art.215/216 da Carta Magna que usa as formas, os processos e os veículos existentes no plano dos meios de comunicação social (Art.220 e segs. da Lei Maior) para eficientemente propalar seus valores na sociedade da informação em que vivemos.

Trata-se, pois, de encontrar solução jurídica para discussão do tema, não só em face da já indicada "convergência de três normas constitucionais: a que prevê o ensino religioso (artigo 210, parágrafo $1^{\circ}$ ), a que assegura a liberdade religiosa (artigo $5^{\circ}$, inciso VI) e a que consagra o princípio da laicidade do Estado (artigo 19, inciso I)" (BRASIL, 2017, online) mas também em decorrência de uma necessária reflexão a respeito da laicidade como desenvolvida por Ayuso (2015) mas necessariamente a partir do balizamento jurídico constitucional destinado a tutelar o uso dos bens culturais reservados à transmissão de conhecimentos religiosos nos espaços difusos articulado com as modernas formas, os processos ou os veículos autorizados pela Lei Maior.

Com efeito, um estudo da Ancine (Agência Nacional de Cinema), divulgado, em agosto de 2017, constatou o absoluto domínio da programação de cunho religioso na grade das principais emissoras de TV aberta no Brasil sendo certo que o relatório vinculado ao estudo mencionado constata "expressivo crescimento desse tipo de obra pelo menos desde 2012, volume que ultrapassa os demais gêneros de obras em 2013, atingindo e ultrapassando a marca de um quinto de todo o conteúdo programado em 2014 e 2015, respectivamente" (STYCER, 2017, online) dando uma ideia do domínio desse tipo de programação - responsável por 21\% do tempo total na grade. ${ }^{2} \mathrm{O}$ referido estudo abrange o conteúdo veiculado em 2016 por Band, CNT, Globo, Record, RedeTV!, SBT, TV Brasil, TV Cultura e TV Gazeta, em São Paulo (as denominadas "cabeças-de-rede nacionais", cuja programação chega a vários estados do Brasil). ${ }^{3}$

Em contrapartida, conforme estudo feito pelo Comitê Gestor da Internet no Brasil (CGI.br), pelo Centro Regional de Estudos para o Desenvolvimento da Sociedade da Informação (Cetic.br) e pelo Núcleo de Informação e Coordenação do Ponto BR (NIC.br) divulgado em 2016, estudo que mede a posse, o uso, o acesso e os hábitos da população brasileira em relação às tecnologias de informação e de comunicação, 58\% da população brasileira usa a internet, o que representa 102 milhões de internautas.

Constatamos, pois, que "la relación entre Derecho y la sociedade actual se da em el contexto de um capitalismo teñido de globalización em uma sociedade altamente informatizada" como advertem Altmark e Quiroga (2012, p. 2).

Destarte, as formas de transmissão de conhecimentos religiosos, na sociedade contemporânea, passaram a ter novo e necessário enquadramento jurídico constitucional em decorrência de seu notório impacto e relevância para uma população de mais de 207.000.000 de pessoas. 
Por via de consequência, um novo tratamento jurídico destinado a estruturar a matéria foi dado de forma mais ampla por nossa Lei Maior não só adstrito à sua tutela jurídica no âmbito do meio ambiente cultural (arts. 215/216) como evidentemente em face da nova realidade que apresenta para todos os brasileiros e estrangeiros residentes no País os desafios destinados a interpretar de forma adequada os balizamentos normativos dos bens culturais veiculados no campo da comunicação social em face do meio ambiente digital em nossa sociedade da informação (arts. 220 e segs da CF).

Cuida-se, portanto, de interpretar juridicamente de que forma a transmissão de conhecimentos religiosos, para as pessoas de todas as idades, estudantes de escolas públicas, estudantes de escolas privadas e mesmo aqueles que não estudam, pode legalmente se desenvolver dentro do atual processo de comunicação como um "fenómeno social en el que participan los comunicadores y los receptores intercambiando reciprocamente sus papeles" como lembra Hoffmann-Riem (1996, p. 46) e no âmbito de uma sociedade da informação em que "la creación, la distribución y el aceceso a la información y la cultura son los motores y finalidades principales de las atividades culturales" como destaca Delpech (2014, p. 89).

É o que vamos abordar no presente artigo, desenvolvido por meio de pesquisa realizada a partir do método hermenêutico, mediante o levantamento dos trabalhos doutrinários elaborados por estudiosos especializados atuantes no âmbito da matéria analisada e da análise jurídica vinculada ao direito ambiental constitucional assim como das normas infraconstitucionais tudo com o objetivo de demonstrar a existência de satisfatório enquadramento do tema em face de nosso sistema jurídico constitucional em vigor e particularmente do direito ambiental constitucional.

Para tanto, desenvolveremos o tema, abordando a liberdade de crença e a tutela jurídica das religiões em face do meio ambiente cultural, das religiões associadas às questões existenciais surgidas em diferentes culturas e, em nosso país, vinculadas ao modo de viver dos diferentes grupos formadores da sociedade brasileira (arts. 215 e 216 da CF) e à transmissão de conhecimentos religiosos na sociedade da informação como manifestação cultural dos grupos participantes do processo civilizatório nacional em face da tutela jurídica do meio ambiente digital. (arts. 220 a 224 da Constituição Federal).

\section{LIBERDADE DE CRENÇA E A TUTELA JURÍDICA DAS RELIGIÕES EM FACEDOMEIO AMBIENTE CULTURAL: AS RELIGIÕES ASSOCIADAS ÀS QUESTÕES EXISTENCIAIS SURGIDAS EM DIFERENTES CULTURAS E, EMNOSSOPAÍS, VINCULADAS AOMODODE VIVER DOS DIFERENTES GRUPOS FORMADORES DA SOCIEDADE BRASILEIRA (ARTS. 215 E 216 $\mathrm{DA} C F)$}

Como adverte Alfonso Santiago:

La relevância social del fenómeno religioso ha cobrado, a comienzos del siglo XXI, una intensidade que no deja de sorprender a quienes prestan atención 
al dinamismo social de nuestro tempo. Contrariamente a lo que profetizaron algunos filósofos modernos, como COMTE, MARX o NIETZSCHE, quienes anunciaban el debilitamiento y hasta la desaparición del hecho religioso, la cuestión religiosa y su influencia en la vida política,tanto a nível nacional como internacional, ha cobrado una creciente importância e actualidad en la realidad social, política, mediática, académica y magisterial de nuestros días (SANTIAGO, 2015, p. 115).

Com efeito.

Para Jung (1983, p. 82),

Religião é - como diz o vocábulo latino religere - uma acurada e conscienciosa observação daquilo que Rudolf Otto acertadamente chamou de 'numinoso', isto é, uma existência ou um efeito dinâmico não causados por um ato arbitrário. Pelo contrário, o efeito se apodera e domina o sujeito humano, mais sua vítima do que seu criador. Qualquer que seja sua causa, o numinoso constitui uma condição do sujeito e é independente de sua vontade. De qualquer modo, tal como o consensus, a doutrina religiosa mostra-nos invariavelmente e em toda a parte que esta condição deve estar ligada a uma causa externa do indivíduo. O numinoso pode ser a propriedade de um objeto visível, ou o influxo de uma presença invisível, que produzem uma modificação especial na consciência. Tal é, pelo menos, a regra universal.

Em contrapartida, ensinam Hellern, Notaker e Gaarder (2001) que, dentre as várias formas de religião registradas durante toda a história, podemos explicar como uma das tentativas possíveis no sentido de localizar como elas teriam surgido, a possibilidade de que o homem logo teria começado a ver as coisas ao seu redor como animadas, acreditando que os animais, as plantas, os rios, as montanhas, o sol, a lua e as estrelas continham espíritos, os quais era fundamental apaziguar. Essa crença, batizada pelo antropólogo E. B. Tylor (1832-1917) de animismo, ainda que discutível hoje, sem dúvida alguma, já relacionava a pessoa humana em face do meio ambiente natural. Os referidos autores indicam algumas definições de religião que consideram famosas, como a de Schleiermacher ("A religião é um sentimento ou uma sensação de absoluta dependência"), a de Tiele, ("Religião significa a relação entre o homem e o poder sobre-humano no qual ele acredita ou do qual se sente dependente. Essa relação se expressa em emoções especiais - confiança, medo - conceitos - crença - e ações - culto e ética"), bem como a de Glasenapp ("A religião é a convicção de que existem poderes transcendentes, pessoais ou impessoais, que atuam no mundo e se expressa por insight, pensamento, sentimento, intenção e ação"). (NOTAKER; GAARDER; HELLERN, 2001, p. 71).

Assim, "abrangendo elementos espirituais, pessoais e sociais" e "sendo "fenômeno que aparece em todas as culturas, desde a Pré-História até hoje, conforme evidenciado nas pinturas das cavernas, nos costumes funerários de nossos ancestrais distantes e na contínua busca por um objetivo espiritual na vida" (AMBALU, 2014, p. 26), as religiões, enquanto diferentes relações existentes entre a pessoa humana e o chamado poder sobre-humano no qual ela acredita ou da qual se sente dependente, ${ }^{4}$ sempre estiveram associadas às questões existenciais surgidas em diferentes culturas e, em nosso país, absolutamente vinculadas ao 
modo de viver dos diferentes grupos formadores da sociedade brasileira, o que gerou a existência de um verdadeiro politeísmo estabelecido por nosso processo civilizatório. De acordo com os dados do IBGE de 2010, referido politeísmo indica a existência de inúmeros grupos religiosos em nosso País. Dentre os 25 maiores grupos religiosos do Brasil, considerando o número total de pessoas que se manifestaram adeptas de cada grupo e observando ainda que, além desses grupos, havia, na época, mais 17 milhões de pessoas ligadas a outros grupos religiosos, pessoas que não souberam especificar e mais 15 milhões de brasileiros que se declararam sem religião ou ateus, ${ }^{5}$ destacam-se os seguintes: 1.a igreja Católica Apostólica Romana, grupo religioso predominante no Brasil, com 123.280.172 seguidores, ou 65\% da população do País em 2010 (o Brasil continua sendo a maior nação católica do mundo); 2. a Assembleia de Deus, maior denominação evangélica pentecostal do País , com 12.314.410 fiéis; 3. os Espíritas com 3.848.876; 4. a igreja Batista com 3.723.853 5. a Congregação Cristã no Brasil reunindo 2.289.634 pessoas; 6.a igreja Universal do Reino de Deus, com 1.873.243 seguidores; 7. a igreja pentecostal do Evangelho Quadrangular, com 1.808.389 brasileiros; 8. a igreja evangélica Adventista, ou Adventista do Sétimo Dia, com 1.561.071 membros no Brasil. 9. as Testemunhas de Jeová, com 1.393.208 adeptos no Brasil; 10. os Luteranos que somam 999.498 pessoas;11. a igreja Presbiteriana, reunindo 921.209 adeptos; 12. Deus é Amor, com 845.383 seguidores 13.a igreja Católica Apostólica Brasileira com 560.781 seguidores; 14. a Umbanda com 407.331 adeptos no Brasil;15. a igreja pentecostal Maranata, com 356.021 seguidores; 16. Os Metodistas com 340.938 seguidores; 17. o Budismo com 243.966 praticantes;18. a denominação Jesus Cristo dos Santos dos Últimos Dias, conhecida como igreja Mórmon, com 226.509 seguidores; 19. a igreja O Brasil Para Cristo, Evangelho Quadrangular, que tem 196.665 fiéis ;20. O Candomblé, religião derivada do animismo africano, reunindo 167.363; 21. a igreja Católica Ortodoxa, congregando 131.571 adeptos; 22. a igreja Casa da Benção, com 125.550 seguidores no país;23. a igreja Congregacional do Brasil com 109.591 adeptos;24. o Judaísmo reunindo 107.326 pessoas e 25. a Messiânica Mundial com 103.716 seguidores. ${ }^{6}$

Embora a religião possa expressar-se em emoções especiais (confiança, medo) e ações fundadas em determinada ética, restou bem evidenciada por nossa Carta Magna a proteção dos conceitos (crença) e ações (culto) expressados em aludido pacto.

Destarte, ao garantir a liberdade de crença a brasileiros e a estrangeiros residentes no País, na forma do que estabelece o art. 5ํ, VI, da Constituição Federal, procurou-se inicialmente nosso direito positivo, como explica Fiorillo (2017, p. 433)

Resguardar a religião fundamentalmente em seus aspectos conceituais (em que a crença se revela como fator intelectual da religião em face de um conjunto de ideias sobre ela que se expressam por cerimônias religiosas - ritos - pela arte e principalmente pela linguagem) como direito material constitucional coletivo, não se olvidando da liberdade de crença também como direito material constitucional individual. 
Por via de consequência, trata-se de observar, como explica Mello Filho (1986), a existência de verdadeira "cláusula constitucional”, com previsão em Constituições anteriores (1824-art. 179, IV e V; 1891-art.72, parágrafos 3º, 12, 28 e 29); 1934-art 113, n. 46 e 9); 1937 (art. 122, n. 4 e 15); 1946 (art.141, parágrafos $5^{\circ}$ e $7^{\circ}$ a $9^{\circ}$ ) e 1967-art.150,parágrafos $5^{\circ}$ a $8^{\circ}$ ), verdadeiro "princípio consagrado pela legislação dos povos civilizados" (CAVALCANTI, 1952, p. 186) esvaziado "de qualquer elemento de desigualdade, ou de despotismo(preponderância)" sendo também "direito individual fundamental, que independe de qualquer escalonamento, em virtude de maior ou menor grupo de adeptos, ou de outro fator diferente" como advertia Miranda (1987, p. 92)

A religião como direito material constitucional metaindividual está associada ao crente em face de determinado conceito com "ideias bem definidas sobre como a comunidade e o mundo vieram a existir, sobre a divindade e o sentido da vida" (NOTAKER; GAARDER; HELLEM, 2001, p. 211), configurando o repertório de ideias da religião que justamente se expressam por cerimônias religiosas (ritos) e pela arte, mas, em primeiro lugar, pela linguagem, tendo como exemplo de referidas expressões as "escrituras sagradas, os credos, as doutrinas ou mitos”, na lição de Notaker, Gaarder e Hellern (2001).

O repertório de ideias da religião está por via de consequência associado à referência, à identidade, à ação, à memória dos diferentes grupos formadores da sociedade brasileira, o que significa dizer que as religiões no Brasil estão intimamente ligadas aos grupos participantes do processo civilizatório nacional, possibilitando-nos afirmar que existem, em nosso país, ideias de religião associadas às manifestações das culturas populares, indígenas, afro-brasileiras, assim como de outros grupos participantes do processo civilizatório antes mencionado.

Evidencia-se, pois, que a liberdade de crença assegurada a todo brasileiro e a todo estrangeiro residentes no País, enquanto direito material constitucional metaindividual estruturado em face de cultos religiosos, encontra-se tutelada pelas normas superiores estruturantes do meio ambiente cultural dentro dos parâmetros estabelecidos nos arts. 215 e 216 da Constituição Federal.

Claro está que a liberdade de crença vinculada ao livre exercício dos cultos religiosos se adapta a toda e a qualquer religião que, na condição de bem de natureza imaterial, seja portadora de referência à identidade, à ação, à memória de quaisquer dos grupos formadores da sociedade brasileira mencionados no art. 215, § 1으, da Carta Magna.

Em consequência, o direito de livre exercício dos cultos religiosos (como conjunto das cerimônias de uma religião), assim como a proteção aos locais das cerimônias e às respectivas liturgias assegurada pelo art. 5ㅇ, VI, da Constituição Federal, estende-se para todo e qualquer repertório de ideias da religião em face da proteção constitucional definidora do meio ambiente cultural (arts. 215 e 216 da CF).

Destarte, breve análise da tutela das principais religiões em face das culturas existentes em nosso País e particularmente no âmbito dos 25 grupos destacados pelo IBGE 2010 merece sucinta investigação visando a esclarecer mais bem seu conteúdo. 


\section{TUTELAJURÍDICADA RELIGIÃOEMFACEDAS CULTURAS INDÍGENAS}

Eliade e Couliano (1995) desenvolvem o tema das religiões na América do Sul, destacando, no que se referem às comunidades indígenas, às religiões da floresta tropical, às religiões do Gran Chaco e aos movimentos milenaristas dos tupis-guaranis do Mato Grosso. No tocante à imensa área da selva e dos rios Orenoco e Amazonas, correspondente à área da floresta tropical, povoada por grande número de tribos pertencentes às famílias linguísticas dos arauaques, caraíbas, panos, tucanos e tupis, é possível, segundo os autores, distinguir traços comuns, embora cada grupo tenha sua própria religião ou variante de religião. Todavia, fundamental na experiência religiosa dos índios da floresta tropical

É a existência de um universo invisível que se sobrepõe ao de todos os dias e ao qual só se tem acesso por meio dos estados alterados de consciência, como o sonho, o transe, a visão provocada pela inalação de drogas etc., ou ainda por uma predisposição mística natural ou adquirida por treinamento especial. A sobreposição dos mundos é tal que os seres do outro mundo geralmente assumem formas de animais, como o caimão, a anaconda, o jaguar e o abutre, cuja essência superior apenas os especialistas podem reconhecer. Mas tudo pode ter um prolongamento no invisível, e os sanemás da fronteira entre o Brasil e a Venezuela distinguem oito categorias de hewkulas ou seres ocultos. Entre esses espíritos, os Donos de Animais têm importância especial em certas sociedades, pois se acredita que regulem o afluxo de animais e peixes destinados à alimentação (ELIADE; COULIANO, 1995, p. 68).

No que se refere às religiões da área que ocupa o centro do continente sul-americano, entre o Mato Grosso e os Pampas, conhecida como Gran Chaco - que significa, em língua quíuchua, "terreno de caça" -, povoado pelas famílias linguísticas do zamucos, tupis-guaranis, matacos, guaicurus-cadivéus e arauaques, todas as tribos têm em comum, conforme explicação de Eliade/Couliano, a instituição do xamanismo (termo oriundo de "xamã" - feiticeiro -, que não é propriamente uma religião, mas um conjunto de métodos terapêuticos e extáticos cujo objetivo é obter o contato com o universo paralelo, mas invisível, dos espíritos e o apoio destes últimos na gestão dos assuntos humanos), que se caracteriza pelo emprego de substâncias alucinógenas (banisteriopsis caapi ou iajé, como as mais conhecidas) ou tóxicas (tabaco) e pela presença de cerimônias coletivas de iniciação.

Assim, visando exatamente a proteger as experiências de vida antes indicadas, entendeu por bem nosso sistema normativo reconhecer explicitamente aos índios suas religióes, protegendo-as como manifestação de sua cultura (arts. 231 e 251, § $1^{\circ}$ ) conforme lembra Fiorillo (2017).

Em consequência, a liberdade de crença apontada na Carta Magna também assegura aos índios o livre exercício de seus cultos religiosos, sendo certo que aludida proteção, bem como respectivas cerimônias religiosas (liturgias), merecerá atenção diferenciada em decorrência da grande diversidade de povos e respectivas culturas.

O art. 232 da Carta Magna assegura aos índios, individualmente ou por meio de suas comu- 
nidades e organizações, defender em juízo, com a necessária participação do Ministério Público em todos os atos do processo, sua religião, diante de lesão ou ameaça que eventualmente possa ocorrer, como direito que lhes é garantido em face da tutela constitucional do meio ambiente cultural.

\section{TUTELA JURÍDICA DA RELIGIÃO EMFACEDAS CULTURAS AFRO-BRA- SILEIRAS}

Os cultos afro-brasileiros, entre as religiões de matriz não cristã desenvolvidas no Brasil, surgiram por volta de 1850, a partir de elementos de origens diversas, conforme explicam Eliade e Couliano (1995). Passaram a ser protegidos com o advento da Constituição Federal de 1988, conforme estabelece o seu art. 215, § 1o; portanto considerados parte do patrimônio cultural brasileiro para todos os efeitos estabelecidos pelo art. 216 do Texto Superior.

Assim, como recorda Fiorillo (2000), chamados por causa da origem de seus principais portadores - os escravos traficados da África para o Brasil -, mas também porque até meados do século XX funcionavam exclusivamente como ritos de preservação do estoque cultural dos diferentes grupos étnicos negros que compunham a população dos antigos escravos e seus descendentes, apresentam feições, conforme os autores citados, "autenticamente africanas", como a possessão pelas divindades orixás e a dança extática.

Informa Pierucci e Prandi (1996) que as religiões afro-brasileiras se formaram em diferentes regiões e Estados do Brasil e em diferentes momentos de nossa história. Diante do que foi alegado, passaram a adotar "não só diferentes formas rituais e diferentes versões mitológicas derivadas de tradições africanas diversificadas" (PIERUCCI; PRANDI, 1996, p. 12), como também nome próprio diferente, a saber, o candomblé, na Bahia, o xangô, em Pernambuco e em Alagoas, o tambor de mina, no Maranhão e no Pará, o batuque, no Rio Grande do Sul, a macumba, depois umbanda, no Rio de Janeiro e em São Paulo.

A exemplo de quaisquer das manifestações tuteladas no plano do direito positivo, os cultos religiosos afro-brasileiros são assegurados constitucionalmente, sendo certo que a proteção aos locais em que são realizados, assim como suas liturgias, também é resguardada pelo art. 5으, VI, da Carta Magna.

\section{TUTELAJURÍDICADA RELIGIÃOEMFACEDAS CULTURASDEOUTROS GRUPOSPARTICIPANTESDOPROCESSOCIVILIZATÓRIONACIONAL: AS IGREJAS CRISTÃ ${ }^{7}$}

\subsection{TUTELA JURÍDICA DO CATOLICISMO}

A cultura de outros grupos participantes do processo civilizatório, descrita na Carta Magna em face do art. 215, $\S 1$, está associada à cultura dos imigrantes desde o chamado "descobrimento do Brasil" como lembra Fiorillo (2017). É importante notar que o desco- 
brimento foi um episódio da expansão marítima portuguesa, cujo objetivo fundamental se caracterizava por tentar impor não só o controle das especiarias como implantar o catolicismo no Oriente, além de resguardar a posse das terras demarcadas pelo Tratado de Tordesilhas. Recorda Fiorillo (2017, p. 450) que

Pedro Álvares Cabral hasteou em sua nau capitânia a bandeira da Ordem de Cristo - ordem que possuía jurisdição eclesiástica sobre as terras conquistadas -, sendo certo que, em 26 de abril de 1500, quatro dias depois de ter sido avistado o denominado Monte Pascoal em terras brasileiras, foi realizada a primeira missa, assistida com curiosidade pelos nativos. Em $1^{\circ}$ de maio de 1500, uma cruz, com as armas e divisas reais, foi erguida na costa brasileira, assinalando não só a posse da terra para Portugal mas o início de um longo período de imposição do catolicismo como religião 'oficial' em nosso país.

A expressão igreja católica, segundo Hans Kung, foi usada, pela primeira vez, por Inácio, o Bispo da Antioquia, em sua carta à comunidade em Esmirna, significando simplesmente a igreja "inteira" - em oposição às igrejas individuais e locais. O conhecido consultor teológico ensina que referida expressão denota uma igreja abrangente e universal, cuja realidade estava sendo sentida de forma cada vez mais clara; mais tarde, ela seria chamada em latim de eclesia catholica ou universalis.

Explicava o saudoso Paulo Evaristo, Cardeal Arns, que "também hoje, quando dizemos 'Igreja Católica', pensamos na comunidade de fiéis batizados, que se encontram no mundo todo." (ARNS, 1981, p. 116).

Destarte, o catolicismo, na condição de conjunto de dogmas, instituições e preceitos da Igreja Católica, é baseado na Bíblia, vista à luz da tradição, ${ }^{8}$ tendo, segundo os autores de $\bigcirc$ livro das religiões, Notaker, Gaarder e Hellern (2001, p. 201), quatro características, a saber:

a) ela é una, ou seja, "fiéis à palavra de Jesus acerca da unidade, os apóstolos se esforçaram para garantir que todos os cristãos aprendessem a mesma fé e a mesma maneira de viver uma vida cristã". A expressão "Igreja una" significa ainda que existe apenas uma única e verdadeira Igreja, e não várias;

b) ela é santa, ou seja, na afirmação do catecismo católico, "a Igreja é santa porque ensina uma doutrina santa e oferece a todos os meios para a santidade, os sacramentos";

c) ela é católica, a saber, "ela é universal, mundial, para todos", na medida em que "os primeiros cristãos atenderam o pedido de Jesus para levar o evangelho a todas as pessoas, e a Igreja continua enviando missões para o mundo inteiro" e;

d) ela é apostólica, vale dizer, "comandada por pessoas que são os sucessores dos apóstolos, permanecendo fiéis à doutrina deles."

Ainda hegemônica no Brasil, a religião católica apostólica romana foi como lembra Fiorillo (2017, p. 414):

[...] a religião oficial do Império, conforme estabelecia o art. $5^{\underline{0}}$ da Constituição Política do Império do Brasil, jurada em 25 de março de $1824 .{ }^{9}$ A República estabeleceu clara ruptura em face da situação ocorrida no Império ao disciplinar que "nenhum culto ou igreja gozará de subvenção official, nem terá relações de dependencia ou alliança com 
o Governo da União, ou dos Estados" (art. 72, § 7ํㅡㄹ da Constituição da República dos Estados Unidos do Brasil, promulgada em 24-2-1891), destacando inclusive, em sua declaração de direitos, que "todos os indivíduos e confissões religiosas podem exercer publicamente o seu culto, associando-se para esse fim e adquirindo bens, observadas as disposições do direito commum" (art. 72, § 3oㅡ, da Carta Magna de 1891).

A Igreja Católica, ao estabelecer algumas características distintivas, indica o importante papel da Virgem Maria, assim como dos santos, para os crentes; imagens e estátuas da Virgem, dos santos e também do Menino Jesus são encontradas por toda a parte nos países católicos.

Desnecessário aduzir que, por sua importância para o povo brasileiro, que inclusive desenvolve anualmente grandes festas religiosas para enaltecer sua fé, o catolicismo recebe a tutela constitucional vinculado ao meio ambiente cultural como manifestação plenamente protegida em face dos arts. 215 e 216 da Carta Magna. Qualquer lesão ou ameaça à liberdade de crença vinculada aos preceitos da Igreja Católica, assim como do livre exercício de seu culto, merecerá, a exemplo das outras culturas antes referidas, a imediata proteção por parte do Poder Judiciário".

\subsection{TUTELA DO PROTESTANTISMO (EVANGÉLICOS)}

Argumenta Pierucci e Prandi (1996) que, no Brasil, as religiões mais importantes em número de seguidores são as cristãs, sendo certo que, depois do catolicismo, vem, "em segundo lugar, o protestantismo." Registre-se que, no Brasil, o termo "evangélico" é genérico para todos os protestantes, ${ }^{10}$ ou seja, usando o termo "evangélico" como sinônimo de protestante, o autor argumenta que são os números que insistem em dizer que o Brasil é mesmo, como um dia chegou a se chamar, a "Terra da Santa Cruz", uma terra de cristãos.

Correspondente nos anos 90 a 9\% da população, segundo o IBGE, os evangélicos vêm ganhando muitos adeptos no Brasil conforme já tivemos oportunidade de indicar anteriormente.

Tendo aportado no Brasil principalmente com os imigrantes e evidentemente em face de sua cultura, no final do século XIX, já estavam implantadas, no Brasil, todas as denominações clássicas do protestantismo, surgindo, na primeira década do século $\mathrm{XX}$, as igrejas pentecostais, que, na segunda metade do mesmo século, cresceram tanto que acabaram por se desenvolver, inclusive em face do que se procurou convencionar como sendo igrejas neopentecostais, vindo a se tornar amplamente majoritárias entre os protestantes brasileiros.

Como manifestação das culturas de vários grupos participantes do processo civilizatório nacional, os protestantes (evangélicos) têm assegurado constitucionalmente não só a inviolabilidade de crença como também o exercício de seus cultos, garantindo-se, em face do que determina o art. 5o-, VI, da Constituição Federal, a proteção aos locais de culto, assim como a suas liturgias. 


\section{TRANSMISSÃODE CONHECIMENTOS RELIGIOSOS NA SOCIEDADEDA INFORMAÇÃO}

Conforme explica Fiorillo (2014, p. 146), "uma das pessoas mais articuladas a tratar a denominada 'sociedade da informação", como ensinam Briggs e Burke (2006), teria sido um jovem norte-americano, Marc Porat, que publicou um artigo, em 1977, denominado, em sua primeira forma, "Implicações globais na sociedade da informação". O texto, como explicam, "havia sido encomendado pela Agência de Informação dos Estados Unidos", sendo certo que a expressão já havia passado para a linguagem usual durante a década de 1960; na época, também a palavra "informação" já havia sido incorporada à expressão "tecnologia da informação"(TI), primeiramente usada nos círculos administrativos e na "teoria da informação" da matemática.

O verbo medieval "enforme, informe", emprestado do francês, conforme explicam Briggs e Burke, "significava dar forma ou modelar", e a nova expressão "sociedade da informação" dava forma ou modelava um conjunto de aspectos relacionados à comunicação - conhecimento, notícias, literatura, entretenimento - todos permutados entre mídias e elementos de mídias diferentes: papel, tinta, telas, pinturas, celuloide, cinema, rádio, televisão e computadores.

Da década de 1960 em diante, todas as mensagens, públicas e privadas, verbais ou visuais, começaram a ser consideradas 'dados', informação que podia ser transmitida, coletada e registrada, qualquer que fosse seu lugar de origem, de preferência por meio de tecnologia eletrônica (HASSEMER, 1997, p. 143).

Iniciando a fase "de la extensión de posiciones jurídicas centenárias en las condiciones particulares de la Edad de la Información” como destaca Hassemer (1997, p. 89).

Destarte, a manifestação do pensamento, a criação, a expressão e a informação da pessoa humana - inclusive evidentemente a transmissão de conhecimentos religiosos passaram no século XXI a ter caráter marcadamente difuso, diante de um novo processo civilizatório representativo da manifestação de novas culturas, particularmente em face das formas, dos processos e dos veículos de comunicação de massa, sobretudo com o uso das ondas eletromagnéticas (Rádio e Televisão), conforme amplamente desenvolvido na obra $\mathrm{O}$ direito de antena em face do direito ambiental brasileiro (FIORILLO, 2000), assim como em face do advento da rede de computadores de alcance mundial formada por inúmeras e diferentes máquinas interconectadas em todo o mundo (Internet).

A transmissão de conhecimentos religiosos na Sociedade da Informação passou a ser estruturada não só em face do que estabelecem os dispositivos constitucionais indicados na "convergência de três normas constitucionais: a que prevê o ensino religioso (artigo 210, parágrafo $1^{\circ}$ ), a que assegura a liberdade religiosa (artigo $5^{\circ}$, inciso VI) e a que consagra o princípio da laicidade do Estado (artigo 19, inciso I)" (BRASIL, 2017, online), mas fundamentalmente em face das regras constitucionais de comunicação social (arts.220 a 224) adaptadas à tutela jurídica da religião como bem cultural (arts.215/216 da CF)., ou seja, as regras de tutela jurídica constitucional da religião em face do meio ambiente digital na sociedade da informação. 


\subsection{A TRANSMISSÃO DE CONHECIMENTOS RELIGIOSOS NA SOCIEDADE DA INFORMAÇÃO COMO MANIFESTAÇÃO CULTURAL DOS GRUPOS PARTICI- PANTES DO PROCESSO CIVILIZATÓRIO NACIONAL EM FACE DA TUTELA JURÍDICA DO MEIO AMBIENTE DIGITAL}

Caracterizada como uma das formas de expressão, assim como observada como uma das manifestações das culturas populares bem como dos grupos participantes de nosso processo civilizatório nacional, a religião, conforme já aduzido anteriormente, está tutelada pelo meio ambiente cultural no plano constitucional (arts. 215 e 216 da CF).

Em referido contexto e articulada no âmbito da comunicação social (art. 220 da CF) procura divulgar bem como informar seu conteúdo por meio das formas, dos processos e dos veículos usados pela pessoa humana na sociedade contemporânea, que, em face de seu atual estágio cultural (processo civilizatório nacional em que se encontram), "destina-se a satisfazer suas necessidades dentro de um padrão cultural vinculado à sua dignidade (art. 1ํㅡ, III, da CF) diante da ordem jurídica do capitalismo (art.1ํㅡㄹ IV, da CF) e adaptada à tutela jurídica do meio ambiente cultural (arts. 215 e 216 da CF)" como destaca Fiorillo e Ferreira (2017a, p. 59).

Destarte, a religião, analisada no contexto do meio ambiente cultural, manifesta-se no século XXI em nosso País exatamente em face de uma cultura que passa por diversos veículos reveladores de novo processo civilizatório adaptado necessariamente à sociedade da informação, a saber, de nova forma de viver relacionada a uma cultura de convergência em que as emissoras de rádio, televisão, o cinema, os videogames, a Internet, as comunicações por meio de ligações de telefones fixos e celulares etc. moldam uma "nova vida" reveladora de nova faceta do meio ambiente cultural, a saber: o meio ambiente digital.

Cuida-se por via de consequência de balizar a religião também em decorrência das normas constitucionais descritas nos arts. 220 a 224 da Constituição Federal, conforme já aduzimos anteriormente, diante dos arts. 215 e 216, com a segura orientação dos princípios fundamentais indicados nos arts. $1^{\circ}$ ao $4^{\circ}$ de nossa Carta Política em face particularmente da denominada "cultura digital", a saber, estabelecer a tutela jurídica da religião como uma das formas de expressão, dos modos de criar, fazer e viver, realizadas e divulgadas, ou seja, transmitidas, com o uso de diferentes formas, processos ou veículos, como computadores e por intermédio de mensagens multiplataforma que permitem trocar mensagens pelo celular (FIORILLO; FERREIRA, 2017b), observando-se o disposto nas regras de comunicação social determinadas pela Constituição Federal.

A tutela jurídica do meio ambiente digital, por via de consequência, ao estabelecer no âmbito de nosso direito positivo deveres, direitos, obrigações e regime de responsabilidades inerentes à manifestação de pensamento, criação, expressão e informação realizados pela pessoa humana com o uso de diferentes formas, processos ou veículos dentro do pleno exercício dos direitos culturais assegurados a brasileiros e a estrangeiros residentes no País (arts. 215 e $5^{\circ}$ da CF) orientado pelos princípios fundamentais da Constituição Federal (arts. $1^{\circ}$ a $4^{\circ}$ ), 
determina, por via de consequência, a observância dos critérios constitucionais vinculados à transmissão de conhecimentos religiosos na Sociedade da Informação como manifestação cultural dos grupos participantes do processo civilizatório nacional contemporâneo.

Cuida por via de consequência da tutela jurídica da transmissão de conhecimentos religiosos em face dos denominados "espaços difusos" dentro de uma perspectiva da comunicação social infinitamente mais ampla e importante que aquela verificada e veiculada nos denominados "espaços públicos".

\title{
7 CONCLUSÃO
}

Em face de interpretação sistemática de nosso superior ordenamento jurídico em vigor, a transmissão de conhecimentos religiosos, não só aquela destinada aos estudantes de escolas públicas de Ensino Fundamental em nosso País, mas também a que se refere aos brasileiros e aos estrangeiros residentes no Brasil (art.5, caput da CF), tem seu balizamento definido em nosso Estado Democrático de Direito delimitado de forma mais abrangente a partir do conceito jurídico de religião como um bem cultural estruturado em face da tutela jurídica constitucional do meio ambiente cultural (arts.215/216 da Carta Magna), podendo ser validamente desenvolvida e propalada por diferentes formas, processos ou veículos existentes no âmbito da comunicação social (art.220 e segs da CF) como efetiva e eficiente forma de transmitir seus valores na sociedade da informação em que vivemos.

Assim, a discussão jurídica do tema não se esgota, pois tão somente na "convergência de três normas constitucionais: a que prevê o ensino religioso (artigo 210, parágrafo $1^{\circ}$ ), a que assegura a liberdade religiosa (artigo $5^{\circ}$, inciso VI) e a que consagra o princípio da laicidade do Estado (artigo 19, inciso I)” (BRASIL, 2017, online), mas necessariamente a partir de interpretação constitucional sistemática mais ampla com a necessária aplicação do regramento jurídico destinado a tutelar o uso dos espaços difusos destinados não só à transmissão de conhecimentos religiosos na sociedade em que vivemos, mas também à disseminação de toda e qualquer manifestação do pensamento, criação e expressão da pessoa humana visando a assegurar sua dignidade (art.1 $\left.1^{\mathrm{o}}, \mathrm{III}\right)$.

\section{THE TRANSMISSION OF RELIGIOUS KNOWLEDGE IN THE INFORMATION SOCIETY AND ITS LEGAL PROTECTION IN THE FACE OF CONSTITUTIONAL ENVIRONMENTAL LAW}

\begin{abstract}
The transmission of religious knowledge, associated with the existential questions that arise in different cultures and, in our country, linked to the ways of living of the different formative groups of the Brazilian society, has its mark defined in our Democratic State of
\end{abstract}


Law, delimited comprehensively from the legal concept of religion as a cultural property, structured in the face of constitutional legal protection of the cultural environment (arts. 215/166 of the Constitution). This can be validly developed and promoted by different forms, processes or vehicles existing in the field of social communication (art. 220 et seq. of the CF) and legally protected in the digital environment as an effective and efficient way of transmitting values in the information society in which we live. The theme is not definitively resolved, because only in the "convergence of three constitutional norms: that which religious education provides (article 210, paragraph 1), which guarantees religious freedom (article 5, section VI) and that enshrines the principle of laicity (Article 19 (I))", but necessarily from a broader constitutional interpretation (Constitutional Environmental Law) with the necessary application of the legal rule to protect the use of diffuse spaces, intended not only for the transmission of religious knowledge in the society in which we live, but for the dissemination of every manifestation of thought, creation and expression of the human person, in order to assure their dignity (Art.1, III).

Keywords: Religion. Cultural good. Cultural Environment. Digital Environment. Constitutional Environmental law.

\section{TRANSMISIÓN DE CONOCIMIENTOS RELIGIOSOS EN LA SOCIEDAD DE LA INFORMACIÓN Y SU TUTELA JURÍDICA ANTE EL DERECHO AMBIENTAL CONSTITUCIONAL}

\section{RESUMEN}

La transmisión de conocimientos religiosos, asociada a las cuestiones existenciales surgidas en diferentes culturas y, en nuestro país, vinculada a los modos de vivir de los diferentes grupos formadores de la sociedad brasileña, tiene su balizamiento definido en nuestro Estado Democrático de Derecho, delimitada de forma larga a partir del concepto jurídico de religión como un bien cultural estructurado ante la tutela jurídica constitucional del medio ambiente cultural (artículos 215/216 de la Constitución Federal). De esa forma, puede ser válidamente desarrollada y propalada por diferentes formas, procesos o vehículos existentes en el ámbito de la comunicación social (artículos 220 y siguientes de la CF) y tutelada jurídicamente en el plan del medio ambiente digital como efectiva y eficiente forma de transmitir sus valores en la sociedad de la información en que vivemos. El tema no se agota, ya que solamente en la "convergencia de tres normas constitucionales: la que prevé la enseñanza religiosa (artículo 210, párrafo 1er), la que asegura la libertad religiosa (artículo $5^{\circ}$, inciso VI) y la que consagra el principio de la laicidad del Estado (artículo 19, inciso I)", pero necesariamente a partir de interpretación constitucional sistemática más amplia (derecho ambiental constitucional), con la necesaria aplicación del reglamento jurídico destinado a tutelar el uso de los espacios 
difusos destinados no solamente a la transmisión de conocimientos religiosos en la sociedad en que vivimos, pero a la diseminación de toda y cualquier manifestación del pensamiento, a la creación y expresión de la persona humana con el objetivo de asegurar su dignidad (artículo $1^{\mathrm{o}}$, III).

Palabras-clave: Religión. Bien cultural. Medio Ambiente Cultural. Medio Ambiente Digital. Derecho Ambiental Constitucional.

1 A ação foi ajuizada pela Procuradoria-Geral da República (PGR), questionando o ensino religioso confessional (vinculado a uma religião específica), ao considerar que tal ensino deve ser voltado para a história e a doutrina das várias religióes, ensinadas sob uma perspectiva laica e teve como objetivo conferir interpretação conforme a Constituição Federal ao dispositivo da Lei de Diretrizes e Bases da Educação (caput e parágrafos $1^{\circ}$ e $2^{\circ}$ do artigo 33 da Lei no 9.394/1996) e o acordo firmado entre o Brasil e a Santa Sé (artigo 11, parágrafo $1^{\circ}$ ). A Procuradoria-Geral da República defendeu a tese de que a única forma de compatibilizar o caráter laico do Estado brasileiro com o ensino religioso nas escolas públicas consiste na adoção de modelo não confessional, em que a disciplina deve ter como conteúdo programático a exposição das doutrinas, práticas, história e dimensões sociais das diferentes religiões, incluindo posições não religiosas, "sem qualquer tomada de partido por parte dos educadores", e deve ser ministrada por professores regulares da rede pública de ensino, e não por "pessoas vinculadas às igrejas ou a confissões religiosas". No dia 15 de junho de 2015, o Supremo realizou uma audiência pública para discutir o assunto, com a participação de 31 representantes de diversas religiões e de órgãos e entidades ligados à educação, os quais apresentaram seus argumentos sobre a matéria.

2 Seguem os gêneros telejornal (15\%), séries (12\%), variedades (7\%) e televendas (6\%).

3 Abaixo o percentual de programação religiosa exibido por cada emissora em 2016, segundo o levantamento da Ancine:

CNT $-89.6 \%$

RedeTV! - 43,72\%

Record - 22,89\%

Band - 16,24\%

Gazeta $-15.65 \%$

TV Brasil - 1,51\%

Globo - 0,62\%

Cultura - 0,59\%

SBT - 0

4 "Religio est, quae superioris cuiusdam naturae (quam divinam vocant) curam caeremoniamque affert." Cicero, De Inventione Rhetorica, II, p. 147 (religião é aquilo que nos incute zelo e um sentimento de reverência por certa natureza de ordem superior que chamamos divina). Citado por C. G. Jung, Psicologia, cit.

5 Trata-se, pois, segundo as estatísticas do IBGE, do segundo "grupo religioso" existente em nosso País...

6 O número de muçulmanos no Brasil cresceu 29,1\% de 2000 a 2010, segundo o último Censo realizado pelo Instituto Brasileiro de Geografia e Estatística (IBGE). A comunidade passou de 27.239 pessoas para 35.167. No mesmo período, a população brasileira aumentou em $12,3 \%$. As regióes com maiores concentrações de muçulmanos coincidem com as que têm grandes comunidades de origem árabe: o estado de São Paulo em primeiro lugar, seguido do Paraná, Rio Grande do Sul, Rio de Janeiro e Minas Gerais. Mas todas as unidades da federação têm pessoas que se declararam seguidoras da religião.

7 Conforme dados divulgados em pesquisa realizada pelo Pew Research Center dos Estados Unidos, os Estados Unidos da América é o país com maior quantidade de cristãos no planeta, com mais de 246 milhões. Em segundo, aparece o Brasil, com mais de 175 milhões de cristãos e, em terceiro, o México, com 107 milhões de cristãos. A pesquisa aponta que do total de cristãos no mundo: 51,4\% são católicos, 36\% são evangélicos e 12,6\% são ortodoxos. 
8 A tradição diz respeito à doutrina e aos costumes que foram transmitidos pela Igreja desde a época dos apóstolos. "O que quer que se entenda por Tradição há uma crença católica comum que diz que apenas a Igreja, e não o crente como indivíduo, pode definir o que é Tradição." (NOTAKER; GAARDER; HELLERN, 2001, p. 289).

9 "Art. 5 A Religião Catholica Apostolica Romana continuará a ser a Religião do Império. Todas as outras Religiões serão permitidas com seu culto doméstico, ou particular em casas para isso destinadas, sem forma alguma exterior de Templo."

10 A Reforma Protestante, que ocorreu no século XVI na Europa Ocidental, levou a profundas mudanças na esfera religiosa, tendo causas políticas (muitos monarcas estavam insatisfeitos com o enorme poder que o Papa exercia no mundo) e propriamente religiosas (muitos teólogos criticavam a doutrina e as práticas da Igreja Católica, sua atitude para com a fé e seu feitio organizacional).

\section{REFERÊNCIAS}

ALTMARK, Daniel Ricardo; QUIROGA, Eduardo Molina. Tratado de derecho informático. Buenos Aires: La Ley, 2012.

AMBALU, Shulamit et al. O livro das religiões. São Paulo: Globo Livros, 2014.

ARNS, Paulo Evaristo. O que é Igreja. São Paulo: Brasiliense, 1981.

AYUSO, Miguel. Del Lacismo a la Laicidad: unas reflexiones (no exclusivamente) Españolas in Retos del derecho constitucional contemporâneo. Buenos Aires: Astrea, 2015.

BRASIL. Supremo Tribunal Federal. STF inicia julgamento que discute ensino religioso nas escolas públicas. Notícias STF, Brasília, DF, 30 ago. 2017. Disponível em: <http://www.stf. jus.br/portal/cms/vernoticiadetalhe.asp?idconteudo=354202 >. Acesso em: 30 ago. 2017.

BRIGGS, Asa; BURKE, Peter. Uma história social da mídia: de Gutenberg à Internet. Rio de Janeiro: Zahar, 2006.

CAVALCANTI, Themistocles Brandão. A Constituição Federal Comentada. Rio de Janeiro: José Konfino Editor, 1952.

DELPECH, Horacio Fernández. Manual de derecho informático. Buenos Aitres: Abeledo Perrot, 2014.

ELIADE, Mircea; COULIANO, Ioan P. Dicionário das religiões. São Paulo: Martins Fontes, 1995.

FIORILlO, Celso Antonio Pacheco. Curso de direito ambiental brasileiro. São Paulo: Saraiva, 2017.

. O Direito de Antena em face do Direito Ambiental no Brasil. São Paulo: Saraiva, 2000. raiva, 2014.

. Princípios constitucionais do direito da sociedade da informação. São Paulo: Sa- 
FIORILLO, Celso Antonio Pacheco; FERREIRA, Renata Marques. Liberdade de expressão e direito de resposta na Sociedade da Informação. Rio de Janeiro: Lumen Juris, 2017a.

. Tutela Jurídica do Whatsapp na Sociedade da Informação. Rio de Janeiro: Lumen Juris, 2017b.

HASSEMER, Winfried. El derecho a la autodeterminación informativa y los retos del procesamiento automatizado de datos personales. Buenos Aires: Editores del Puerto, 1997. HOFFMANN-RIEM, Wolfgang. Libertad de comunicación y de médios. In: BENDA, Ernest et al. Manual de derecho constitucional. Madrid: Marcial Pons, 1996.

JUNG, Carl G. Psicologia da religião ocidental e oriental. Petrópolis: Vozes, 1983.

MELlO FILHO, José Celso. Constituição Federal Anotada. São Paulo: Saraiva, 1986.

MIRANDA, Pontes. Comentários à Constituição de 1967. Rio de Janeiro: Forense, 1987.

NOTAKER, Henry; GAARDER, Jostein; HELLERN, Victor. O livro das religiões. São Paulo: Cia. das Letras, 2001.

PIERUCCI, Antônio Flávio; PRANDI, Reginaldo. A realidade social das religiões no Brasil. São Paulo: Hucitec, 1996.

SANTIAGO, Alfonso. Las relaciones entre religión y política en la sociedad postsecular del siglo XXI. In: RESTREPO, Gabriel Mora; ROJAS, Vicente Fábian Benítez. Retos del derecho constitucional contemporâneo. Buenos Aires: Astrea, 2015.

STYCER, Mauricio Stycer. Programação religiosa ocupa 21\% da grade da TV aberta no Brasil. 2017. Disponível em: < https://mauriciostycer.blogosfera.uol.com.br/2017/08/25/programacao-religiosa-ocupa-21-da-grade-da-tv-aberta-no-brasil-ve-ancine/?cmpid=copiaecola $>$. Acesso em: 30 ago. 2017.

Submetido: 2 set. 2017

Aprovado: 23 out. 2017 